\title{
The Synaptic Connections between Cortical Areas V1 and V2 in Macaque Monkey
}

\author{
John C. Anderson and Kevan A. C. Martin \\ Institute for Neuroinformatics, University of Zürich and ETH Zürich, 8057 Zürich, Switzerland
}

The primary visual cortex (V1) and V2 together form $\sim 24 \%$ of the total neocortex of the macaque monkey and have each other as their major partners. The major target of the V1 projection to V2 is layer 4, where it forms clusters of boutons, which form asymmetric (excitatory) synapses mainly with dendritic spines $(75 \%)$. The remainder form synapses with dendritic shafts. The synapses found on spines were often more complex, perforated postsynaptic densities than those found on dendritic shafts. The reciprocal projection from V2 to V1 targeted layers 1,2/3, and 5 and was formed of axons of different morphologies. One axon type, originating from superficial layer pyramidal cells, had a morphology resembling those of local pyramidal cell collaterals. These axons arborized in layers 1, 2/3, and 5 of V1. Another type of axon, arborizing in layer 1, was slender $(0.3 \mu \mathrm{m})$, unbranched, unmyelinated, and uniformly covered with boutons terminaux and formed asymmetric synapses mainly with slender spines. Yet a third type of axon also confined to layer 1, was thick $(>1$ $\mu \mathrm{m})$, branched, heavily myelinated, and formed separate small clusters of large $(\sim 1 \mu \mathrm{m})$ en passant multisynaptic boutons that formed asymmetric synapses mainly with large flat spines. These data show the existence of a reciprocal excitatory loop between V1 and V2 that is formed by different axonal types, each with preferred layers of termination.

\section{Introduction}

The first two cortical visual areas in the macaque monkey are approximately equal in size and together form $\sim 24 \%$ of the total surface area of the macaque cortex (Felleman and Van Essen, 1991). Quantitative studies by Kennedy and colleagues (Barone et al., 2000; Kennedy et al., 2000) show that $88 \%$ of the corticocortical projection neurons of V2 project to $\mathrm{V} 1$ and $81 \%$ of the corticocortical projection neurons in V1 project to V2 (Kennedy et al., 2000). The output from V1 to V2 divides into separate anatomical streams that map onto the patches of cytochrome oxidase staining in V1 and V2 (Livingstone and Hubel, 1983, 1984), although they now seem more mixed than originally supposed (Sincich and Horton, 2002a,b, 2005a,b).

There is a fundamental puzzle in the V1-V2 relationship. V1 is in a recurrent excitatory loop with $\mathrm{V} 2$, yet, when $\mathrm{V} 1$ is inactivated it virtually eliminates all activity in retinotopically related areas of V2 (Girard and Bullier, 1989), whereas the reverse is not true: inactivating V2 has little impact on most V1 neurons (Hupé et al., 2001). Why with such rich reciprocal connectivity is there such an asymmetrical effect? Although the inactivation experiments were performed under general anesthesia, it is clear that the depressing effects of anesthesia are not responsible, because the V2 neurons remain active and well driven by visual stimuli. Such asymmetrical effects, which are seen elsewhere (the geniculocortical loop,

\footnotetext{
Received Dec. 3, 2008; revised Aug. 4, 2009; accepted Aug. 7, 2009.

This work was funded by European Union (QULG3-1999-01064), Human Frontier Science Program (RG0123/ 2000-B), and Swiss National Science Foundation grants to K.A.C.M.

Correspondence should be addressed to either John C. Anderson or Kevan A. C. Martin, Institute for Neuroinformatics, University of Zürich and ETH Zürich, Winterthurerstrasse 190, 8057 Zürich, Switzerland, E-mail: jca@ini.phys.ethz.ch or kevan@ini.phys.ethz.ch.

DOI:10.1523/JNEUROSCI.5757-08.2009

Copyright $\odot 2009$ Society for Neuroscience $\quad$ 0270-6474/09/2911283-11\$15.00/0
}

for example) are usually explained by the hypothesis that "feedforward" projections (e.g., V1 to V2) "drive" their target neurons, whereas "feedback" projections (e.g., V2 to V1) only "modulate" their target neurons (Hupé et al., 2001; Guillery and Sherman, 2002). This "explanation" begs the basic question of what possible biophysical differences could account for this profound difference in effect.

Perhaps driving inputs must enter at layer 4, which is the main thalamic recipient layer and, by definition, the main target of corticocortical feedforward projections? However, thalamocortical synapses form only $\sim 10 \%$ of the excitatory synapses in layer 4 of V1 (Latawiec et al., 2000), which means that most projections to layer 4 do not drive cortex. Another possibility is that the feedback synapses are simply less effective than feedforward synapses. This is the preferred explanation of Guillery and Sherman (2002), for whom the geniculocortical loop is a cardinal example. In their view, axons of driving projections have large en passant boutons forming multiple complex contacts, while the small terminaux boutons of modulating projections form simple axodendritic contacts. Even under anesthesia, V1 neurons can be driven by electrical stimulation of V2 (Girard et al., 2001). In addition, Rockland and Virga $(1989,1990)$ found a complex picture of three different laminar patterns of termination for axons projecting from $\mathrm{V} 1$ to $\mathrm{V} 2$ and two major patterns for axons projecting from $\mathrm{V} 2$ to $\mathrm{V} 1$ and there may be yet additional complexities associated with the projections between the cytochrome oxidase compartments. Here we search for clues to differences in the effects of feedforward and feedback projections, by studying their ultrastructure.

\section{Materials and Methods}

The material presented here was taken from four adult male macaque monkeys and one adult female (Macaca mulatta), which were used in 
Table 1. Location and properties of tracer injections, axon distributions, and bouton numbers

\begin{tabular}{|c|c|c|c|c|c|c|c|c|}
\hline $\begin{array}{l}\text { Animal } \\
\text { reference }\end{array}$ & $\begin{array}{l}\text { Visual area } \\
\text { injected }\end{array}$ & $\begin{array}{l}\text { Tracer injected } \\
\text { and method }\end{array}$ & $\begin{array}{l}\text { Tracer injection } \\
\text { size }(\mu \mathrm{m})\end{array}$ & $\begin{array}{l}\text { Layers } \\
\text { injected }\end{array}$ & $\begin{array}{l}\text { Number of } \\
\text { injections }\end{array}$ & $\begin{array}{l}\text { Survival } \\
\text { time (d) }\end{array}$ & $\begin{array}{l}\text { Labeled material } \\
\text { and target area }\end{array}$ & $\begin{array}{l}\text { Boutons } \\
\text { examined }\end{array}$ \\
\hline M1 & V1 & Biocytin ionophoretic & 320 diam. & $2 / 3$ & 1 & 1 & Bouton clusters in V2 & 77 \\
\hline $\mathrm{M} 2$ & V1 & BDA ionophoretic & 220 wide & $2-6$ & 3 & 10 & Bouton clusters in V2 & 30 \\
\hline M3 & V2 & BDA ionophoretic & 150 diam. & $2 / 3$ & 2 & 12 & Bouton cluster in V1 & 59 \\
\hline M4 & V2 & PHA-L pressure & 320 wide & $3-6$ & 3 & 1.5 & "Thin" axon in V1 & 44 \\
\hline M5 & V2 & PHA-L pressure & 150 wide & $3-6$ & 4 & 10 & "Thick" axon in V1 & 34 \\
\hline
\end{tabular}

acute electrophysiological experiments. Animal treatment and surgical protocols were performed in accordance with the guidelines of the Kantonal Veterinaeramt of Zurich. The following procedures are similar to those used by Anderson and Martin (2002). Animals were prepared for surgery after the administration of an intramuscular premedication of xylazine (Rompun, Beyelar, $0.5 \mathrm{mg} / \mathrm{kg}$ )/ketamine (Ketalar, Parke Davis, $10 \mathrm{mg} / \mathrm{kg}$ ). This was followed by cannulation of a femoral vein for the delivery of alfaxalone/alphadolone (Saffan, Glaxo) to establish complete anesthesia.

Animals received from 1 to 4 injections of neuronal tracer (see Table 1). Biocytin (Sigma) was delivered as a $4 \%$ solution in Tris buffered $\mathrm{KCl}(0.2 \mathrm{M})$, biotinylated dextran amine (BDA) (Invitrogen) as a $10 \%$ solution in $0.01 \mathrm{M}$ PBS, $\mathrm{pH} 7.4$, and Phaseolus vulgaris leucoagglutinin (PHA-L) (Vector Laboratories) as a $2.5 \%$ solution in $0.01 \mathrm{M} \mathrm{PBS}, \mathrm{pH}$ 7.4. The ionophoretic injections were made with a glass micropipette using a pulsed ionophoretic current of $2-4 \mathrm{~mA}$ over a $7-10$ min period. After a $1-10 \mathrm{~d}$ survival period, the animals were very deeply anesthetized with intravenous pentobarbital $(20 \mathrm{mg} /$ $\mathrm{kg}$ ) and then perfused transcardially with a normal saline solution, followed by a solution of $3.5 \%$ paraformaldehyde, $0.8 \%$ gluteraldehyde, and $15 \%$ picric acid in $0.1 \mathrm{M} \mathrm{PB}, \mathrm{pH}$ 7.4. A block of cortex containing the injection site and areas V1/V2 was removed and sunk in sucrose solutions of 10,20 , and $30 \%$ in $0.1 \mathrm{M} \mathrm{PB}$, then freeze-thawed in liquid nitrogen and washed in $0.1 \mathrm{M}$ PB. Sections were cut from the block at $80 \mu \mathrm{m}$ in the parasagittal plane and collected in $0.1 \mathrm{M} \mathrm{PB}$. We used standard procedures to reveal the neuronal tracers. In brief outline; washes in PBS were followed by $10 \%$ normal swine serum (NSS) in PBS ( $1 \mathrm{~h}$ ). When appropriate the antibody to PHA-L was diluted in the above at 1:200 and exposed for $48 \mathrm{~h}$ at $5^{\circ} \mathrm{C}$. Further washes in NSS preceded overnight exposure $\left(5^{\circ} \mathrm{C}\right)$ to an avidin-biotin complex (Vector ABC kit, Elite). The peroxidase activity was identified using 3,3diaminobenzidine tetrahydrochloride (DAB). After assessment by light microscopy, selected regions of tissue were treated with $1 \%$ osmium tetroxide in $0.1 \mathrm{M} \mathrm{PB}$. Dehydration through alcohols ( $1 \%$ uranyl acetate in the $70 \%$ alcohol) and propylene oxide allowed flat mounting in Durcupan (Fluka) on glass slides.

Light microscopic observations of labeled axons were performed to locate and select regions of interest for electron microscopy. We reconstructed individual collaterals in the less densely innervated areas for correlated light and electron microscopy. Serial ultrathin sections were collected at 60 or $70 \mathrm{~nm}$ thickness on Pioloform-coated single slot copper grids. Labeled boutons were photographed at a magnification of 21,000. Synapses and associated structures were classified using conventional criteria (Peters et al., 1991). Collections of serial sections were digitized and reconstructed using Trakem, an in-house EM-digitization package. To measure and display the postsynaptic densities of labeled boutons we used software developed by ourselves, which has been described in out- line previously [see Anderson et al. (1998), their Materials and Methods]. We used a Philips CM100 electron microscope fitted with a Morada camera and ITM software. For figure preparation we used Adobe Illustrator CS3 and Photoshop CS3.

\section{Results}

\section{Light microscopy}

Each of the five monkeys received ionophoretic injections of BDA, PHA-L, or biocytin that were confined to the gray matter of either area V1 (two cases) or area V2 (three cases).

$V 1$ to $V 2$

The injections into area V1 were placed at $\sim 7-8 \mathrm{~mm}$ distance posterior to the lunate sulcus, well inside area V1 (see Fig. 1A). Two V1 injection sites were located in superficial layers and two injection sites involved all layers and labeled cells in layers 2-6. Dense labeling of cell bodies at most injection sites extended 0.2 $\mathrm{mm}$ to $0.3 \mathrm{~mm}$ from the penetration, although the appearance of label at the different injection sites varied. The termination zone of the BDA-labeled axons originating from the injection site illustrated in Figure $1 A$ extended over $\sim 2 \mathrm{~mm}$ of layer 4 on the posterior bank of the lunate sulcus in V2, with the denser innervation located closer to the tip of the gyrus. The axon termination zone in the other V1-injected monkey was located in three dis- 

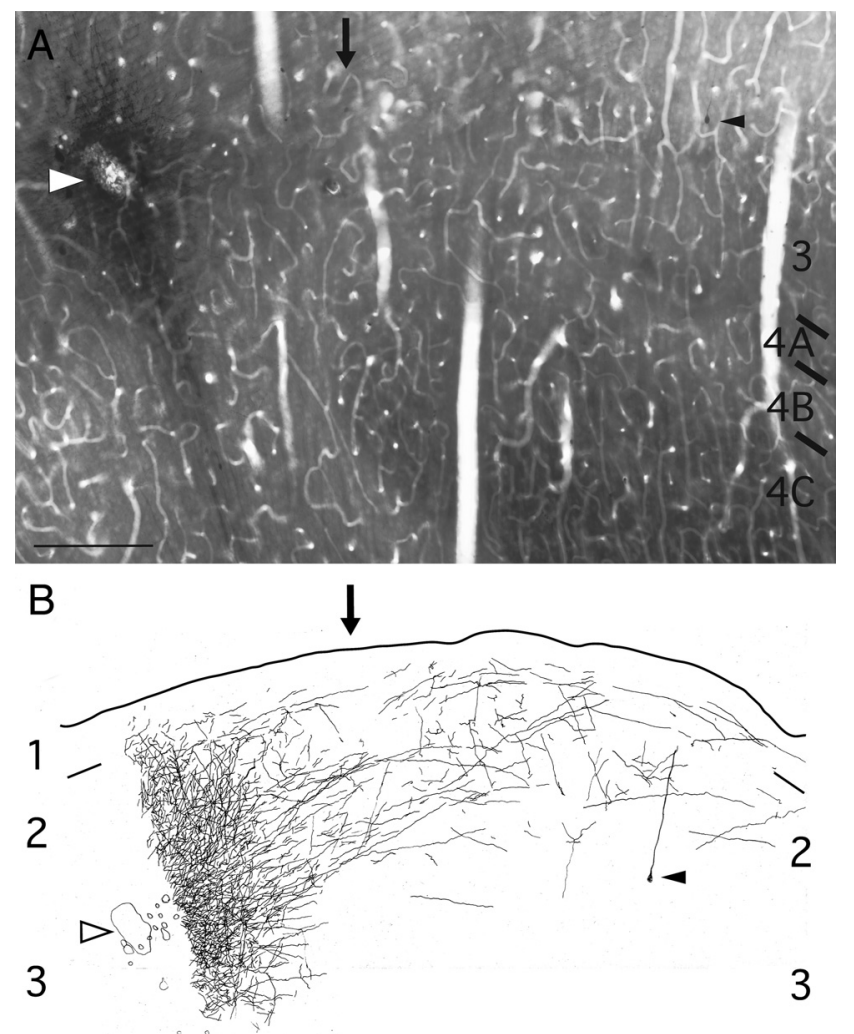

Figure 2. Location of injection site in V2. $\boldsymbol{A}$, Light photomontage of a parasagittal section through the cortex at the border between V1 and V2 (arrow) showing the injection site in V2 (white arrowhead) and the location of a weak retrogradely labeled pyramidal cell (arrowhead). V1 laminae are indicated to the right. $\boldsymbol{B}$, Light microscopic drawing of the section shown in $\boldsymbol{A}$. Anterogradely labeled axons projecting from the injection site (open arrowhead) cross the border into V2. Axons in the immediate vicinity of the injection site were not drawn because the density of label was too intense. The position of the weakly labeled pyramidal cell shown in $\boldsymbol{A}$ is indicated (arrowhead). Laminae and their borders are indicated to the left and right. Scale bars, $300 \mu \mathrm{m}$.

crete clusters within the fundus of the lunate sulcus. Each cluster had a lateral spread within layer 4 ranging from 0.3 to $0.5 \mathrm{~mm}$, separated by similarly sized zones that were relatively bouton free. Collaterals arising at the border of white matter and layer 6 were followed through the deep layers to their extensive arborizations layer 4. In one animal a few fibers entered lower layer 3. Both animals showed very little retrograde labeling of cell bodies. Axons traversing the deeper layers were myelinated, so often only the cut ends of these axons had strong reaction product. Upon reaching layer 4 the collaterals became unmyelinated, branched frequently, and became finer, and formed boutons, which were mainly en passant $(\sim 78 \%)$ in morphology (Fig. $1 B)$. The sheer density of innervation in layer 4 made it impossible to reconstruct individual axons or accurately to correlate LM and EM.

\section{V2 to $V 1$}

The injections in area V2 were made at the tip of the lunate gyrus and were confined to the gray matter. In the first animal only the superficial layers two and three were labeled with BDA (Fig. 2), while in the other two animals all layers of the cortex were labeled (Anderson and Martin, 2002, their Fig. 1A). In all three animals there was retrograde labeling of pyramidal cells in layers 2 and 3 of $\mathrm{V} 1$, although much less in the first animal where the injections were more localized (see Fig. 2). The axons of the retrogradely labeled cells arborized mainly in layers $2 / 3$ and 5 but also pro-

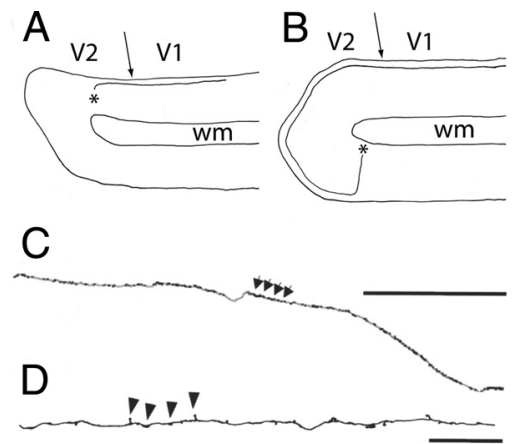

E

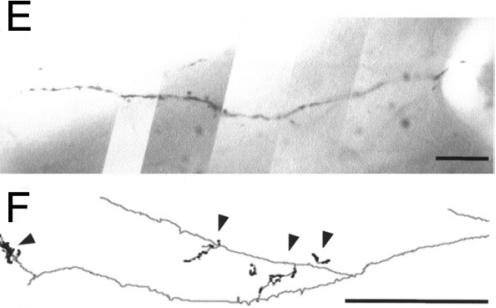

G
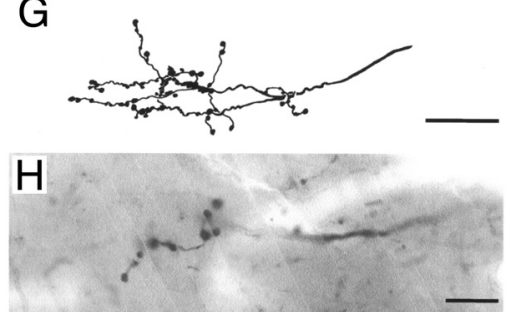

Figure 3. Two "feedback" axons labeled with PHA-L, confined to layer 1 and showing terminations in area V1. $\boldsymbol{A}, \boldsymbol{B}$, Low-power sketches of lunate gyrus showing approximate path of two axons through layer 1 and earliest appearance of axon (asterisk). The white matter (wm) and V1-V2 border are also indicated (arrow). Axon shown in $\boldsymbol{A}$ and $\boldsymbol{C} \boldsymbol{E}$ is referred to as the "thin" axon. C, Light microscopic reconstruction of the thin axon showing a long, unbranched, bouton encrusted (small filled arrowheads) collateral. D, High-magnification ( $100 \times$ oil objective) light microscopic drawing showing detail of thin axon and frequently located boutons (filled arrowheads). $\boldsymbol{E}$, Light microscopic photomontage of thin axon in layer 1. Axon shown in $\boldsymbol{F}-\boldsymbol{H}$ is referred to as the "thick" axon. $\boldsymbol{F}$, Light microscopic reconstruction of thick, branched axon showing clusters of boutons (solid arrowheads). The computer assisted 3-D reconstruction of the axon is rotated to provide the view from the surface of the brain. $G$, High-magnification light microscopic drawing showing detail from one bouton cluster. $\boldsymbol{H}$, Light microscopic photomontage of thick axon and bouton cluster. Scale bars: $\boldsymbol{C}, \boldsymbol{F}, 0.5 \mathrm{~mm} ; \boldsymbol{D}, \boldsymbol{G}, 25 \mu \mathrm{m} ; \boldsymbol{E}, \boldsymbol{H}, 10 \mu \mathrm{m}$.

vided a dense innervation of layer 1 . This meant that the axons originating from pyramidal cells in V2 were mixed with axons originating from pyramidal cells in V1. Even axons traced from the white matter underlying V1 were found to originate from retrogradely labeled pyramidal cells in superficial layers of V1. Hence we examined only those axon collaterals that could be traced back to the injection site and, where possible, to a labeled cell body.

The first animal had a large number of axons originating from the labeled superficial layer pyramidal cells in V2 that did not enter the white matter, but projected laterally from layers $2 / 3$ and 5 to arborize in layers $1,2 / 3$, and 5 of V1 (Fig. 2) and forming boutons over their entire length. The projection to layer 2/3 in V1 was the densest and showed the least retrograde contamination. Of the many labeled axons only a single axon in each of the second and third animals could be traced back to their origins in the injection sites in V2. These single axons also did not dive into the white matter beneath $\mathrm{V} 2$ to reemerge in $\mathrm{V} 1$, but instead were confined to layer 1 throughout their projection from V2 to V1. The morphologies of the two single axons were strikingly different from each other. 
The single axon from the second animal, referred to here as the "thin" axon, emerged from a radially aligned myelinated fiber in layer 1 at a point directly above the infragranular layer injection site in V2, $1.3 \mathrm{~mm}$ from the V1/V2 border. It then abruptly turned right angles to traverse the middle of layer 1 in a posterior direction toward $\mathrm{V} 1$ and remained tangential to the surface of the cortex until its termination in V1. In V1 this axon was very thin $(0.3 \mu \mathrm{m})$, unmyelinated, and unbranched. It had many boutons terminaux distributed over its entire length $(2 \mathrm{~mm})$ in layer 1 (Fig. $3 A, C-E)$. Axons showing this pattern of trajectory have been described by Rockland (1994).

The second single axon from the third animal we will refer to as the "thick" axon. It arose from an injection site in infragranular layers of V2 and traveled radially toward the cortical surface of the posterior bank of the lunate sulcus. Upon reaching layer 1 the axon abruptly turned right angles and traversed V2, remaining tangential to the surface of the cortex. Continuing just above the middle of layer 1 the axon passed around the tip of the lunate gyrus. The labeling of the axon was dark and continuous until it reached the opercular surface of V1, where it became myelinated and the label became intermittent. But in each section, the cut ends of the axon were clearly labeled and the thickness of the axon made it easy to follow despite the absence of continuous label. This axon was thick $(>1 \mu \mathrm{m})$, branched, heavily myelinated, and formed separate, small clusters of large $(\sim 1 \mu \mathrm{m})$ en passant boutons (Fig. 3B, $\mathrm{F}-\mathrm{H}$ ) through the thickness of layer 1 . Some of these V2 to $\mathrm{V} 1$ axon features were also described by Rockland and Virga (1989). The fact that the axons projecting from $\mathrm{V} 2$ to $\mathrm{V} 1$ passed through the gray matter and not the white matter is unusual. However, the injection sites were relatively close to the V1-V2 border and passage through gray matter may be more economical. The axons also formed boutons in the V2 portion of their trajectory.

We have previously described the variations in bouton morphology and density for the axons of spiny neurons (Martin and Whitteridge, 1984; Anderson and Martin, 2001). Boutons are usually recognized as beads along an axon (bouton en passant) or swellings on short processes extending from the axon (bouton terminaux). Using correlated LM and EM we have repeatedly verified here, and in previous studies (Anderson et al., 1998; Anderson and Martin, 2002, 2005, 2006) that boutons identified at light microscope level form synaptic specializations and that synapses in the interbouton segments are rare.
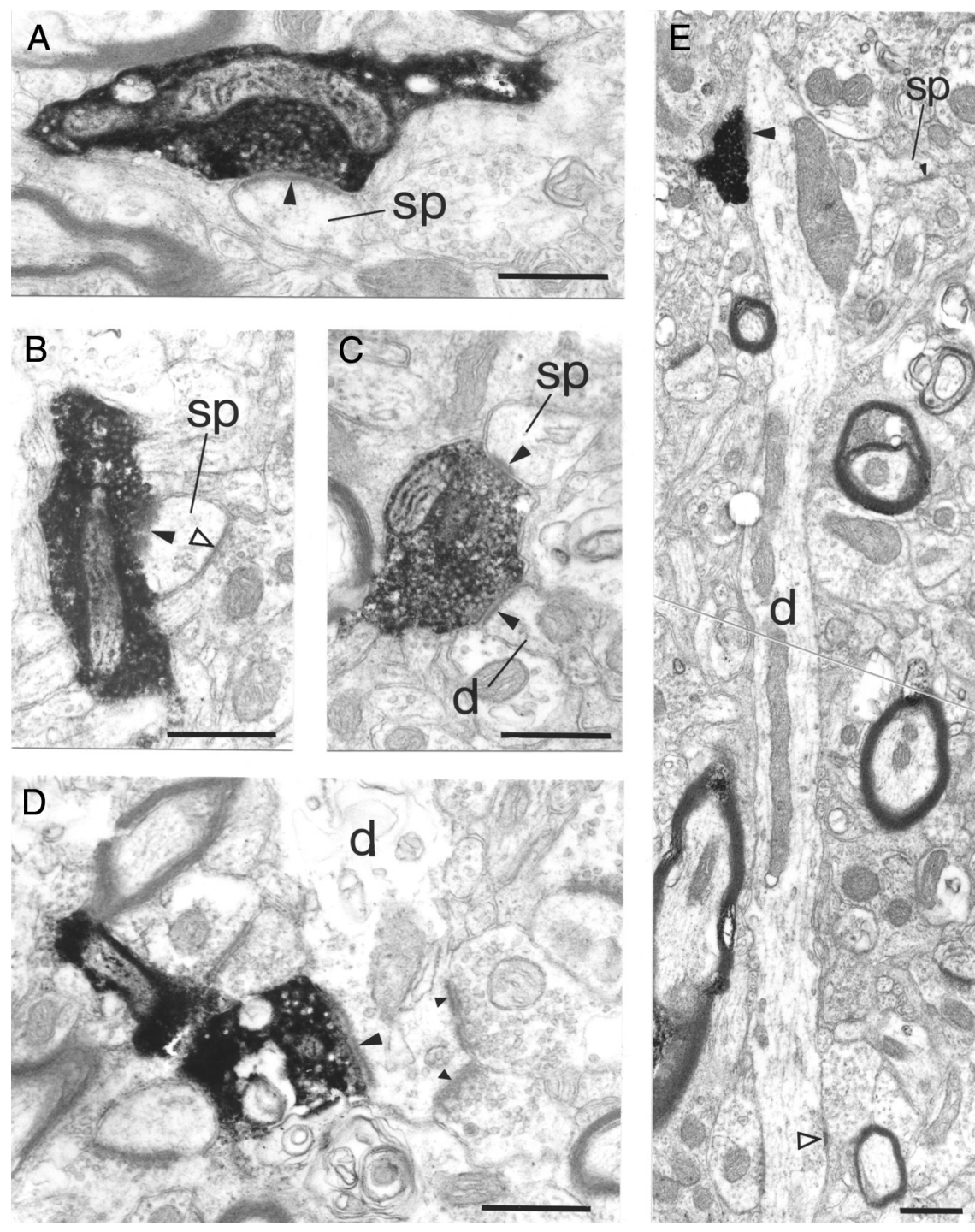

Figure 4. Electron photomicrographs taken from cortical area V2 showing BDA-labeled boutons in layer 4. A, A labeled bouton en passant forms an asymmetric synapse (solid arrowhead) with a spine (sp). $\boldsymbol{B}$, A spine (sp) forms an asymmetric synapse (solid arrowhead) with a labeled bouton and a symmetric synapse (open arrowhead) with an unidentified bouton. The asymmetric synapse of the labeled bouton has been cut rather obliquely obscuring the synaptic cleft and smearing the postsynaptic density. C, A labeled bouton forms two asymmetric synapses (solid arrowheads) with a spine (sp) and a small caliber dendritic shaft (d). D, A large-caliber dendritic shaft (d) forms an asymmetric synapse (solid arrowhead) with a labeled bouton. The dendrite (d) forms a further two asymmetric synapses (small solid arrowheads) with two unidentified boutons. Serial section reconstruction of the dendrites shown in $\boldsymbol{C}$ and $\boldsymbol{D}$ revealed that both formed more synapses and contain numerous mitochondria. These features are characteristic of GABA-containing smooth cells. $\boldsymbol{E}, \mathrm{A}$ lower-power electron micrograph showing a labeled bouton forming an asymmetric synapse (solid arrowhead) with a medium-caliber dendritic shaft (d). The dendrite produces a spine (sp), opposite the labeled bouton, that forms an asymmetric synapse (small solid arrowhead). An unidentified bouton forms a symmetric synapse (open arrowhead) with the dendritic shaft. Dendrites showing few shaft synapses, few mitochondria, and forming spines are features of spiny cells, probably pyramidal cells. Scale bars: $\boldsymbol{A}-\boldsymbol{E}, 0.5 \mu \mathrm{m}$.

\section{Electron microscopy}

We examined a total of 107 labeled V1 boutons in layer 4 of area $\mathrm{V} 2$. The labeled V1 terminals in V2 provided 126 synaptic specializations. For the projection from V2 to V1 we examined 137 boutons, which formed a total of 165 synapses. From the cluster of layer 3 cells labeled in V2 axons, we sampled 59 boutons in layers 1 and $2 / 3$ of $\mathrm{V} 1$, together with 44 boutons in layer 1 of $\mathrm{V} 1$ from the V 2 thin axon and 34 boutons in layer 1 of V1 from the thick axon. The thin axon provided 44 synapses and the thick axon, 61 synapses. All boutons from these individual axons were 

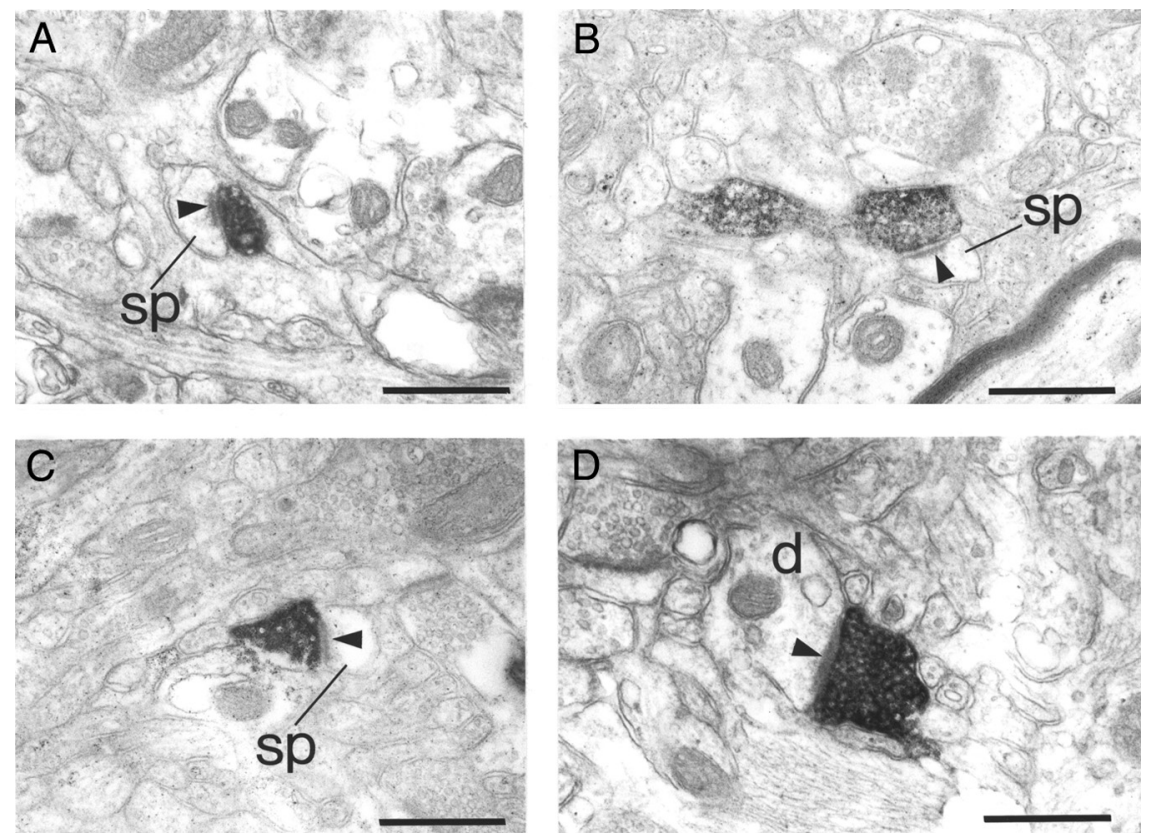

Figure 5. Electron photomicrographs taken from cortical area V1 showing PHA-L-labeled boutons in layer 1. All examples are taken from the "thin" axon (Fig 1; $\boldsymbol{A}-\boldsymbol{C}$. $\boldsymbol{A}$-C , Examples of small boutons forming asymmetric synapses (solid arrowheads) with spines (sp). The majority of labeled boutons and their targets were of similar dimensions. $\boldsymbol{D}, \mathrm{A}$ labeled bouton forms a synapse (solid arrowhead) with a small caliber dendrite (d). The dendrite formed a second synapse with another labeled bouton from the same axon. The ultrastructural characteristics of the dendrite (variable diameter, numerous mitochondria, and forming many synapses) indicate that it is from a GABAergic neuron with smooth dendrites. Scale bars, $0.5 \mu \mathrm{m}$.

serially sectioned and reconstructed. Synapses from V2 boutons in layers 1 and $2 / 3$ were serially sectioned and 27 of 60 were reconstructed. All labeled boutons formed asymmetric synapses (Gray's type 1). Those synapses that were incomplete were excluded from the measurements of the area of the postsynaptic densities.

The reaction end-product was dark, although of variable intensity in different boutons. Vesicles and mitochondria were clearly visible within the boutons and the synaptic clefts were not obscured by diffusion of the label. Myelinated axons were also labeled, indicating that the antibody sometimes had penetrated, despite the barrier to diffusion of the reagents presented by the myelin. Small vacuoles formed in some labeled structures (e.g., Figs. $4 A, D, 6 A)$. The V1 to V2 population showed relatively little variation in bouton size $(\sim 0.5 \mu \mathrm{m})$. Occasionally we found labeled myelinated axons $(0.12-0.5 \mu \mathrm{m}$ diameter $)$ with a myelin wall thickness of $\sim 0.1 \mu \mathrm{m}$. For the V2 to V1 projections, the boutons of the thin axon were uniformly small $(\sim 0.3 \mu \mathrm{m})$ and were mostly bouton terminaux (Figs. 5, 7A). In contrast, the thick axon $(\sim 1 \mu \mathrm{m}$ diameter) formed large bouton en passant $(\sim 1$ $\mu \mathrm{m}$ ) (Figs. 6, 7B) with occasional smaller boutons, such as the small bouton terminaux in Figure $6 D$. The larger the bouton the greater the number of mitochondrial profiles in single sections. The myelin sheath covering the thick axon had a wall thickness of $\sim 0.15 \mu \mathrm{m}$. The very small boutons of the thin axon rarely contained a mitochondrion. Boutons from the thick axon could contain several mitochondria. Single sections of the V1 to V2 boutons of intermediate size usually contained one or two mitochondrial profiles. All the remaining space within the labeled boutons was packed with vesicles, which sometimes extended into the axon (e.g., Fig. 6 E). Synapses were indicated by the presence of vesicles, a synaptic cleft and a postsynaptic density. The postsynaptic density could be a simple disc shape or perforated.

\section{Targets of synaptic boutons: spines}

Serially sectioning the bouton, synapse, and target structures greatly assisted in determining the type of target that formed synapses with the labeled boutons. We also used standard ultrastructural criteria to classify targets (Peters et al., 1991). The most frequent targets of both projections were spines (Figs. 4-6). Occasionally we were able to trace spines back to a parent dendrite (Fig. 6A,C). The target spines of the $\mathrm{V} 1$ to $\mathrm{V} 2$ projection were all small (Fig. $4 A-C)$. A second synapse from an unlabeled bouton was seen on 17 of 91 spines. The second synapse was always of a symmetric morphology (Gray's type 2) (Fig. $4 B)$. This is an unusually high proportion of dual input spines (19\%), but was strongly biased by the data from one animal in particular (14 of 62 spines, 23\%). The second animal provided three dual input spines ( 3 of 29, 10\%), which is closer to the range that is normally encountered in studies of spines and their synapses.

The boutons of the two individual feedback V2 to V1 axons formed synapses with spines of very different sizes. The thin axon boutons formed synapses with spines that were equally tiny (Fig. $7 A$ ). The large boutons of the thick axon formed synapses with spines that were clearly large and flattened when seen after serial section reconstruction (Fig. 7B). Figure 8 shows the reconstructed spines contacted by boutons of the thin (Fig. $8 \mathrm{~A}$ ) and thick (Fig. $8 \mathrm{~B}$ ) axons. Rockland has also noted that the majority of synaptic targets of the feedback projection in layer 1 were spines (Rockland, 1994).

The spine targets of the upper layer $2 / 3$ projecting axons were usually small $(<0.5 \mu \mathrm{m})$ in diameter. Only one bouton of the population of $\mathrm{V} 2$ to $\mathrm{V} 1$ axons shared its target spine with a second (symmetric) synapse. A light and diffuse labeling appeared in some of the smaller spines (Fig. 6A). The label helped us to trace back to the parent dendrite that also showed light labeling. We attributed this light labeling to retrograde uptake of PHA-L at the injection site, which would indicate that neurons that project to $\mathrm{V} 2$ also receive input from V2.

\section{Targets of synaptic boutons: dendritic shafts}

Dendritic shafts were also the targets of labeled boutons. They were usually identified by reconstruction from serial sections, or by the presence of mitochondria and microtubules. Overall, labeled boutons formed synapses with a range of dendrites of different diameters $(\sim 0.5-1.5 \mu \mathrm{m})$. Dendrites sometimes contained numerous vacuoles and ultrastructurally tended to suffer more than spines when they formed synapses with labeled boutons (e.g., Figs. 4D, 6D,E). We have no explanation for this, but it was clearly related to the presence of the label. From the serial section reconstructions we grouped the dendrites into two classes. Sixteen of the 34 synapses from the V1 to V2 synapses in layer 4 were formed with the shafts of dendrites that varied little in diameter and formed very few synapses along the shaft. These features are characteristic of the spiny dendrites of excitatory neurons, a characterization that was occasionally confirmed in this material by spines emerging from the shafts of dendrites with 
these characteristics. Three of the six dendritic shafts that formed synapses with the thin axon and 5 of 14 synapses formed by the thick axon were with shafts of spiny neurons. In one case the thin axon formed two synapses with a target dendrite: one synapse with the shaft and one with a spine.

A second class of dendrite varied in its diameter, it contained numerous mitochondria and formed many shaft synapses with unidentified boutons. These features were usually clearer when the dendrite was serially reconstructed. Neurons with these features have smooth dendrites and have been shown to contain the inhibitory neurotransmitter GABA (Somogyi et al., 1983; Peters and Saint Marie, 1984; Kisvárday et al., 1985; Beaulieu et al., 1992; Ahmed et al., 1997; Meskenaite, 1997). Just over half ( 18 of $34,53 \%$ ) of the target dendrites of the projection from $\mathrm{V} 1$ to V2 were of the smooth type. The V2 to $\mathrm{V} 1$ boutons from the thin axon formed synapses with 3 smooth dendrites. One of these dendrites formed synapses with two labeled boutons. In the case of the thick axon 9 of 14 (64\%) of the dendritic shaft synapses were formed with the dendrites of smooth neurons. Three of the dendrites formed two synapses with boutons of the thick axon (e.g., Fig. 7B). One smooth dendrite also formed numerous tiny processes (Fig. 6E) each of which formed one or two synapses with unidentified boutons. These "spinules" appeared to be headless and varied in length from 0.1 to $0.5 \mu \mathrm{m}$. The ultrastructural morphology was not that of any recognizable excitatory or spiny neuron (e.g., pyramidal cell) but clearly showed features of smooth neurons, perhaps an intrinsic GABAergic neuron of layer 1 . All of the target dendrites (11) from the projection to layers 1 and 2/3 of V1 showed features of smooth dendrites.

\section{Targets of synaptic boutons: somata}

Only one synapse was seen between a labeled bouton and a soma, which was located in layer 4 of V2. There were many organelles within the soma and it also received numerous synapses from unidentified boutons, which are features of smooth neurons.

\section{Postsynaptic density}

Reconstructing the bouton and its target gave us the opportunity to view the complete postsynaptic density (PSD) as a twodimensional (2-D) or 3-D structure. We have used this technique previously to obtain values of the surface area of synapses (Anderson et el., 1998; Anderson and Martin, 2002, 2005, 2006). By focusing on the postsynaptic specialization rather than the presynaptic membrane, we avoided detail being obscured by re-
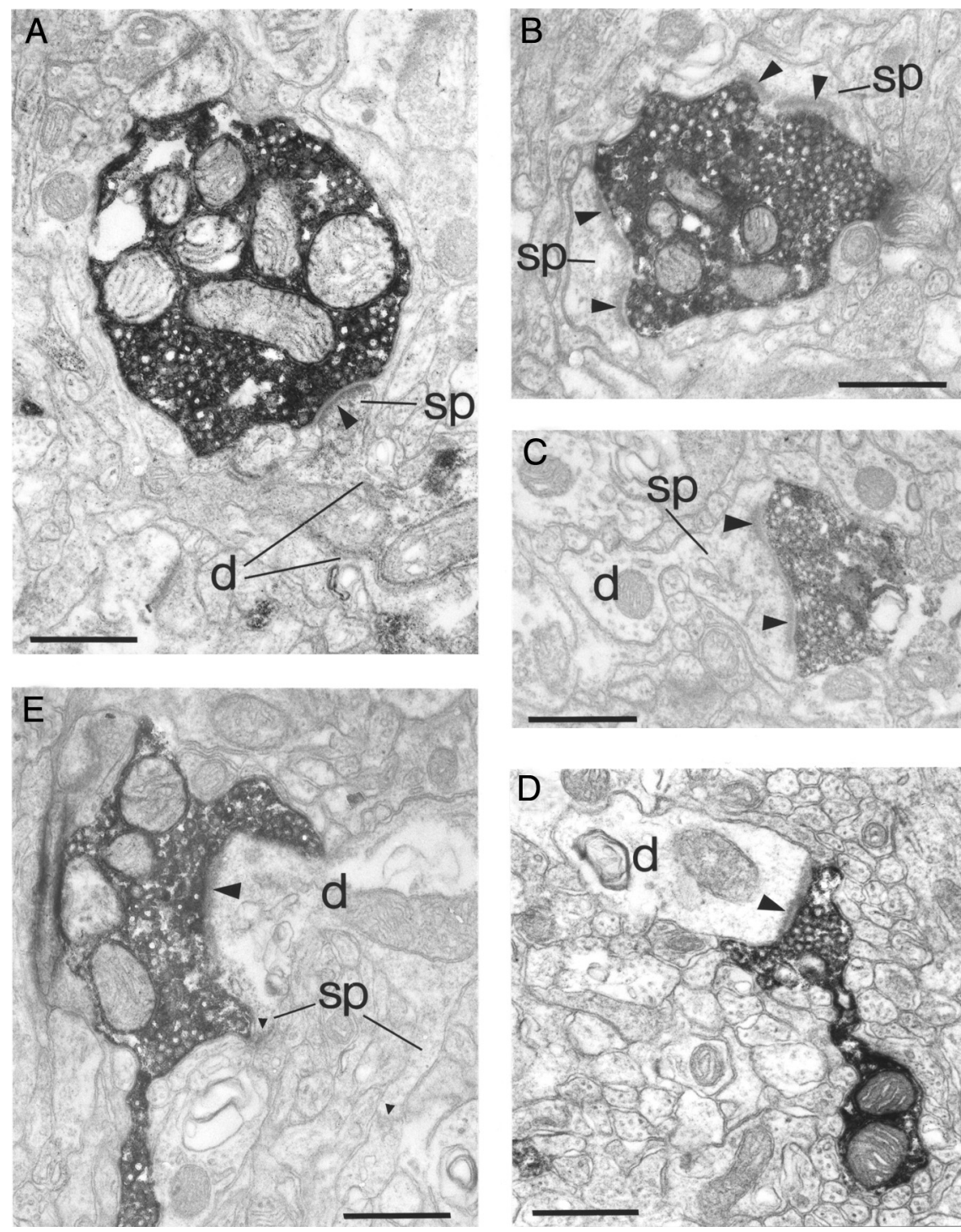

Figure 6. Electron micrographs of PHA-L-labeled boutons forming synapses in layer 1 of area V1. All examples are taken from the "thick" axon (Fig. 1; D-F).A, A large labeled bouton forms an asymmetric synapse (solid arrowhead) with a small spine (sp). The spine and parent dendrite (d) are weakly labeled with retrogradely transported PHA-L. B, Two large spines (sp) each form a perforated asymmetric synapse (solid arrowheads) with a large labeled bouton. $C$, A medium sized bouton forms a perforated asymmetric synapse (solid arrowheads) with a spine (sp) that can be followed back to the small caliber parent dendrite (d). $\boldsymbol{D}, \mathbf{A}$ small bouton terminaux forms an asymmetric synapse (solid arrowhead) with a medium-caliber dendrite (d). The dendrite contained few mitochondria, formed no other synapses and showed little variation in diameter. These features are characteristics of neurons with spiny dendrites, probably pyramidal cells. $\boldsymbol{E}$, A large bouton en passant forms an asymmetric synapse (solid arrowhead) with a large-caliber dendrite (d). The dendrite was unusual in that it formed synapses with the shaft and with small and slender spinous processes that each formed at least one asymmetric synapse (small solid arrowheads). The shaft also contained numerous mitochondria. Scale bars, $0.5 \mu \mathrm{m}$.

action end-product in the bouton. We show a 2-D projection of the PSDs in Figures 9-11. There was no difference seen in the distributions of the areas of synapses made with the two main target types for the V1 to V2 axons, which were spines $(0.081$ $\left.\mu \mathrm{m}^{2}, \mathrm{SEM}, 0.004\right)$ and dendrites $\left(0.077 \mu \mathrm{m}^{2}\right.$, SEM, 0.006) $(p=$ 0.6, two-tailed $t$ test) (Fig. 12).

The data for the projection from V2 to V1 were derived from a random sample taken from superficial layers as well as an extensive series of EMs from two very different single axons, and so were not pooled (Fig. 13). The synapses formed by the thin axon were very small $\left(0.032 \mu \mathrm{m}^{2}\right.$, SEM, 0.004), while those of the thick axon were very large $\left(0.17 \mu \mathrm{m}^{2}\right.$, SEM, 0.016$)$ (Fig. 13) and those 

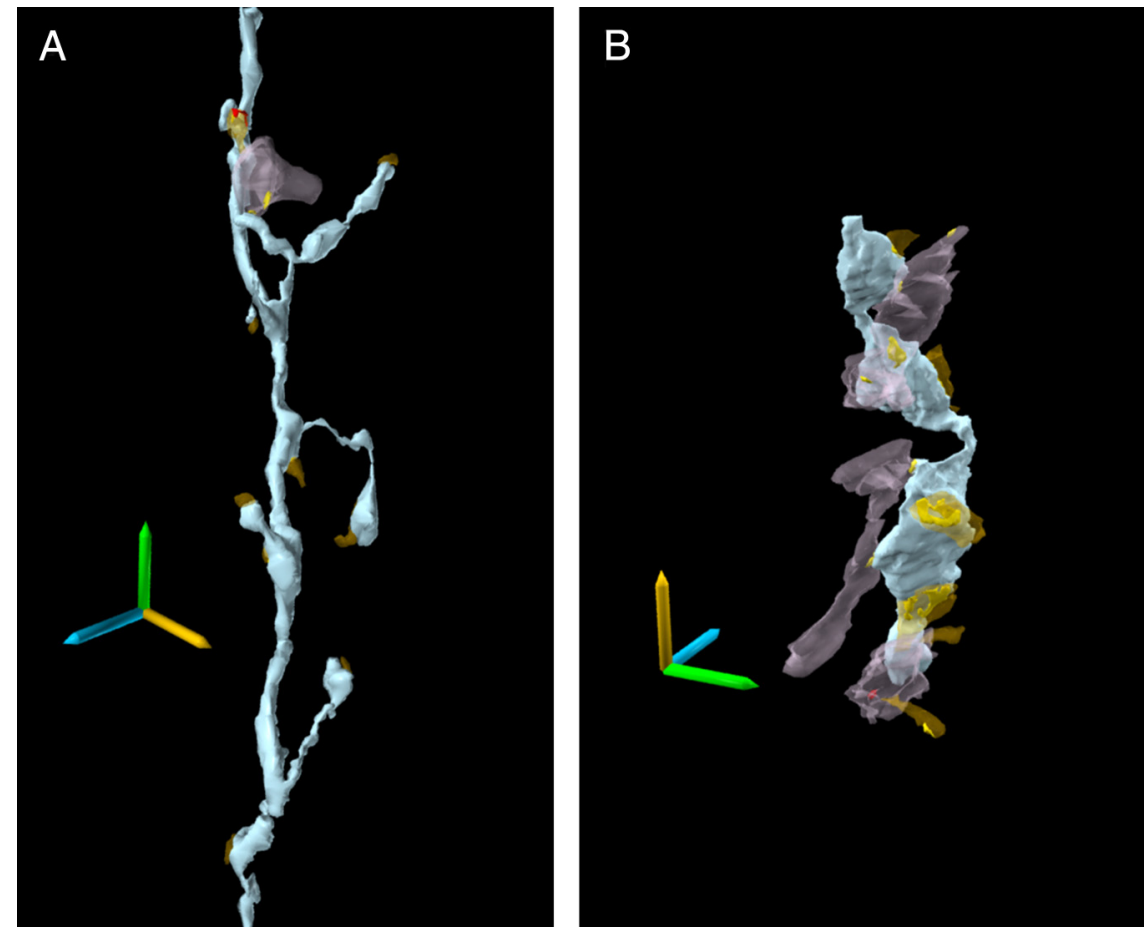

Figure 7. Three-dimensional reconstruction from serial ultrathin sections of PHA-L-labeled boutons in layer 1 of V1 showing synaptic targets. $\boldsymbol{A}$, Thin axon (blue) showing numerous projecting boutons terminaux each forming a single synapse (yellow) in most cases with a small spine (transparent brown). Near the top of the reconstruction a bouton terminaux branches to form two boutons, one of which forms a synapse with a dendritic shaft (transparent mauve). A spine projects from the uppermost surface of the dendrite and forms another synapse with the labeled axon. This same spine also forms a symmetric synapse (red) with an unidentified bouton. $\boldsymbol{B}$, Thick axon (blue) showing a string of three boutons en passant and their synaptic targets; spines (transparent brown) and dendritic shafts (transparent mauve). Postsynaptic densities, often complex, are shown in yellow. The two uppermost boutons each form two synapses, one each with a spine and the second with a dendritic shaft that passes between the two boutons. The dendrite also receives an asymmetric synapse from an unidentified bouton. The lower bouton forms four synapses; two with spines and two with a dendritic shaft. One of the spines can be traced back to the parent dendrite showing more spines and forms an asymmetric synapse (red) on the shaft. Scale bars, $2 \mu \mathrm{m}$.
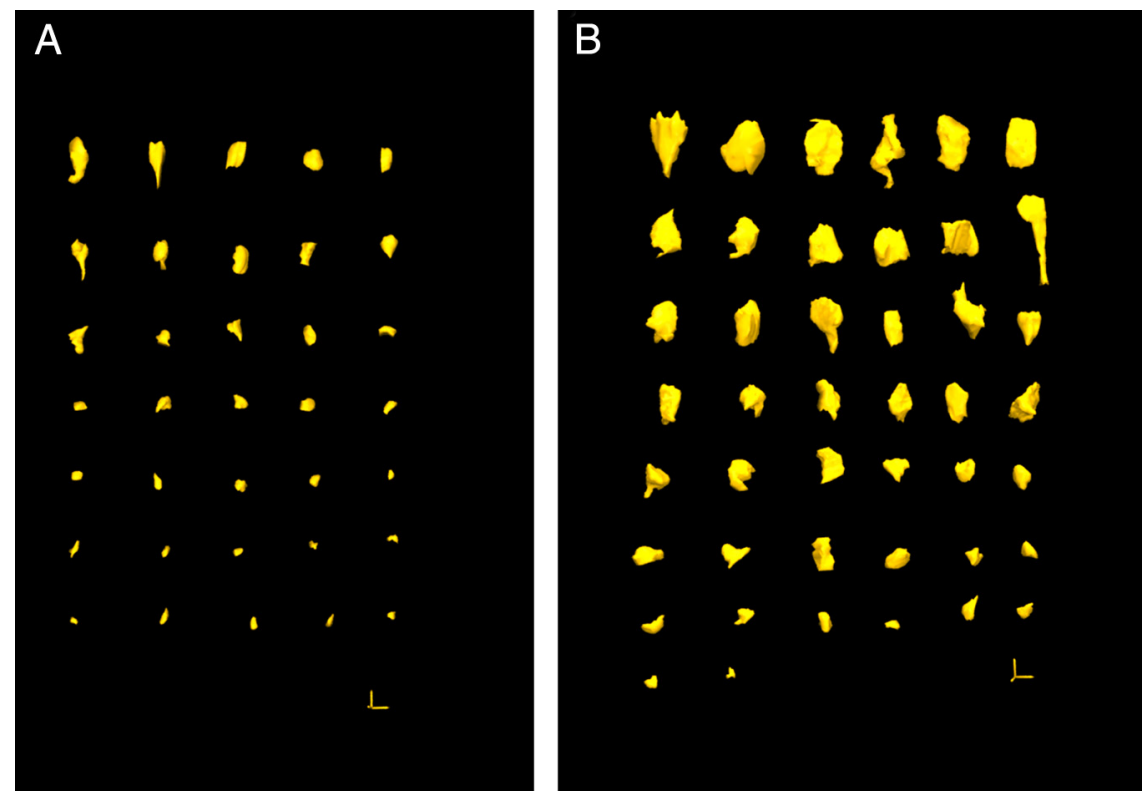

Figure 8. Reconstructed spines found postsynaptic to labeled boutons of thin axon $(\boldsymbol{A})$ and thick axon $(\boldsymbol{B})$. The spines have been ordered roughly by size. Each spine has been rotated to present its broadest face. Scale bars, $0.5 \mu \mathrm{m}$. of the random sample from superficial layers fell between the two $\left(0.08 \mu \mathrm{m}^{2}\right.$, SEM 0.008). The spine synapses formed by the thick axon $\left(0.19 \mu \mathrm{m}^{2}\right.$, SEM, 0.02) were significantly larger than those formed with dendritic shafts $\left(0.10 \mu \mathrm{m}^{2}\right.$, SEM, 0.02) ( $p=0.018$, two-tailed $t$ test). This was also true of the random superficial layer sample (spine $0.08 \mu \mathrm{m}^{2}$, SEM 0.01; dendrite $0.05 \mu \mathrm{m}^{2}$, SEM 0.009; $p=0.029$ two-tailed $t$ test). The PSDs of the thin axon were predominantly simple discshaped structures, while those of the thick axon showed greater complexity in shape with numerous perforations, particularly in spines. PSDs formed with the spines of the V1 to V2 projection also had a complex, perforated morphology, which we have reported in other projections in monkey cortex (Anderson et el., 1998; Anderson and Martin, 2002, 2005, 2006).

\section{Target types}

The most frequently encountered targets of V1-labeled boutons in V2 and for V2labeled boutons in V1 were spines. One clear difference between the various axons was in the proportion of spines to dendrites as targets (Fig. 14). In layer 4 of V2, $72 \%$ of the labeled V1 synapses formed with spines, $27 \%$ with dendritic shafts, and $1 \%$ with somata. In layer 1 of V1, the thin axon from $\mathrm{V} 2$ formed $84 \%$ of its synapses with spines and $16 \%$ with dendritic shafts, whereas the thick axon formed $77 \%$ of its synapses with spines and $23 \%$ with dendritic shafts. In layers 1 and $2 / 3$ of $\mathrm{V} 1$, the proportion of spines to dendritic shafts was similar to that seen for the thin axon in layer 1: $82 \%$ spines and $18 \%$ dendritic shafts. The majority of labeled boutons for all projections formed one synapse, although single boutons could form up to four synapses (Fig. 15). The thin axon from the V1 to V2 pathway only ever formed one synapse per bouton.

\section{Discussion}

\section{Light microscope observations}

We confirmed many of the morphological observations made by Rockland and Virga (1989, 1990). The V1 projection to V2 formed clusters of boutons concentrated in layer 4, but with additional collaterals in layers 3 and 6. Rockland and Virga (1989) described two types of axons projecting from V2 to layer 1 of V1, one of which formed clusters of boutons, and the other that was continuously studded with bouton terminaux, as in our "thin" axon. They, as did we, also observed a third type of axon, which formed en passant boutons principally in layers 5 and 3 of $\mathrm{V} 1$. 


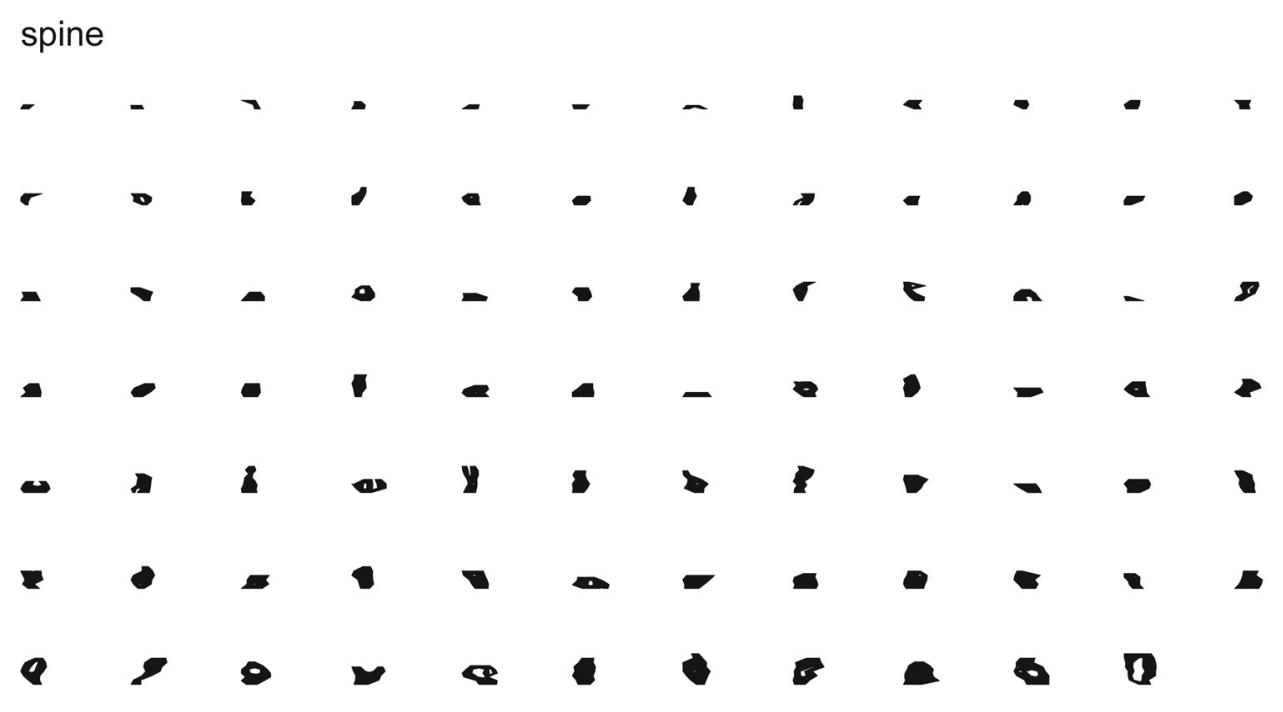

dendrite

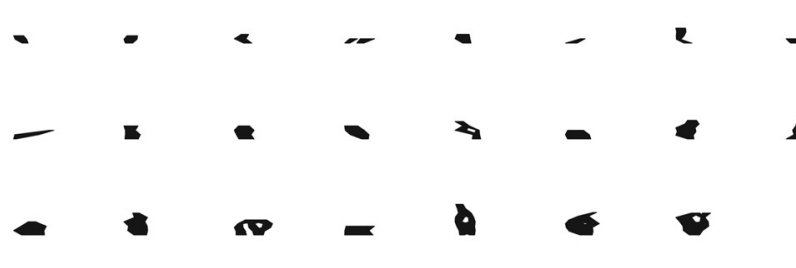

Figure 9. Two-dimensional projection of the reconstructed postsynaptic densities found on spines, soma, and dendrites postsynaptic to V1-labeled boutons in layer 4 of area V2. The densities are ordered by increasing surface area. Scale bar, $1 \mu \mathrm{m}$.

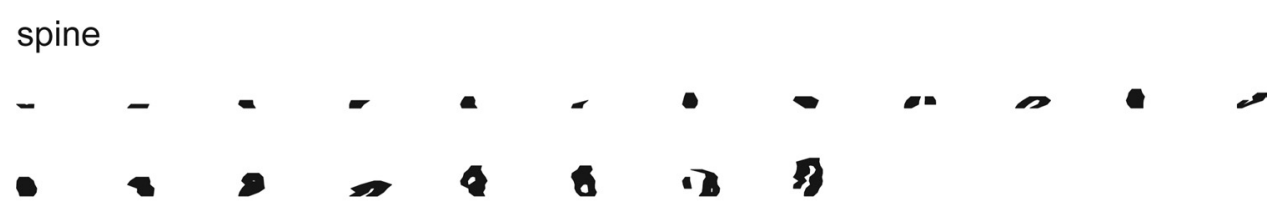

dendrite

Figure 10. Two-dimensional projection of the reconstructed postsynaptic densities found on spines and dendrites postsynaptic to V2-labeled boutons in layers 1 and 2/3 of area V1. The densities are ordered by increasing surface area. Scale bar, $1 \mu \mathrm{m}$.

However, Rockland and Virga's axons emerged from the white matter, whereas the axons we traced streamed across the V1/V2 border in the gray matter, even when the injections were some millimeters from the border. Although the "thick" axon formed clusters of boutons in layer 1, its clusters were more reminiscent of the morphology of Meynert cell axons of macaque V1 (Rockland and Knutson, 2001) than of the type of axon with clustered boutons described by Rockland and Virga (1989). Since large solitary pyramidal neurons are also found in the deep layers of V2, it would be interesting to discover whether these are the source of the thick axons that project to layer 1 of V1.

We could find no morphological evidence to suggest that all the V1 to V2 axons were feedforward "drivers" and all the V2 to V1 axons were feedback "modulators." In the V2 to V1 projection we only recovered one axon (the "thin" axon) that resembled Guillery and Sherman's (2002) description of “modulating axon." The "thick" axon, which projected from V2 to V1, had the features of a "driving axon." Indeed, the most common type of axon we found projecting from the superficial pyramidal cells in V2 to the superficial layers of V1 was morphologically indistinguishable from the axons that projected from V1 to V2.

\section{Ultrastructure of synapses. Postsynaptic density size and spine morphology}

It is evident from the ultrastructure of the target spines that bigger spines have bigger PSDs. This relationship has been reported for pyramidal cells in the hippocampus (Harris and Stevens, 1989) and mouse barrel cortex (Knott et al., 2006). The PSDs of the thin axon were almost one-third the size of most interareal spine synapses $\left(0.032\right.$ versus $\left.\sim 0.1-0.12 \mu \mathrm{m}^{2}\right)$. Most remarkable were the size of the PSDs of the thick axon in layer 1, which were larger $\left(0.19 \mu \mathrm{m}^{2}\right)$ than anything yet reported for macaque cortex. The 


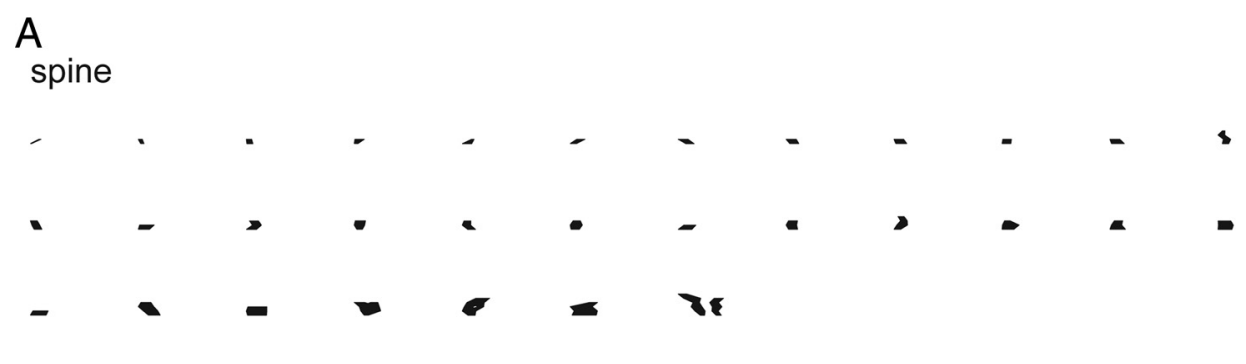

dendrite

B

spine

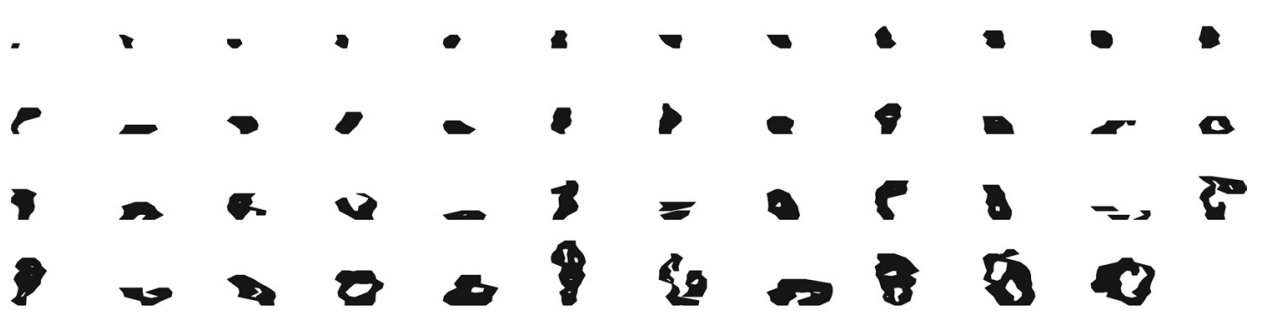

dendrite

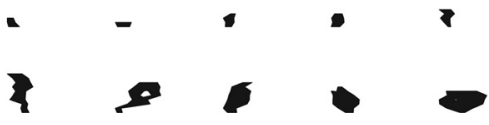

Figure 11. Two-dimensional projection of the reconstructed postsynaptic densities found on the spines and dendrites postsynaptic to labeled boutons in layer 1 of area $V 1$ from thin axon $(\boldsymbol{A})$ and thick axon $(\boldsymbol{B})$. The densities are ordered by increasing surface area. Scale bar, $1 \mu \mathrm{m}$.

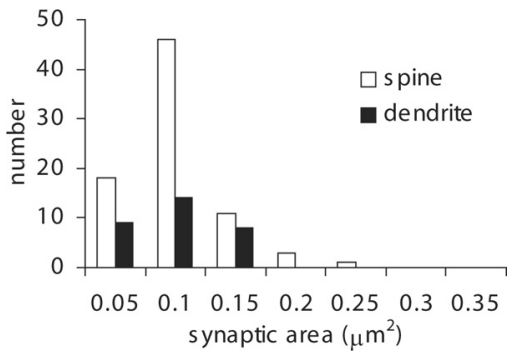

Figure 12. Histogram showing the distributions of postsynaptic areas (in square micrometers) formed with spines and dendrites by labeled V1 boutons in layer 4 of V2.

previous largest were the V1 to MT projection (Anderson et al., 1998), which were $0.127 \mu \mathrm{m}^{2}$. Cortical synapses of comparable size $\left(\sim 0.18 \mu \mathrm{m}^{2}\right)$ have only been seen once before in the thalamic projection to layer 4 of the cat visual cortex (Dehay et al., 1991; Friedlander et al., 1991). The range of areas of the postsynaptic specialization within most single populations of reconstructed synapses is at least an order of magnitude [e.g., V1 to MT (Anderson et al., 1998) and V4 to V2 (Anderson and Martin, 2006)], although the average size between these populations is surprisingly similar. The functional consequences of this variance remains unexplained, as does the correlation we observed between spine size and synapse size. However, the data from Stevens and colleagues indicates that there is a positive correlation between size of synapse and the release probability and amplitude of glutamatergic synapses (Schikorski and Stevens, 1997; Murthy et

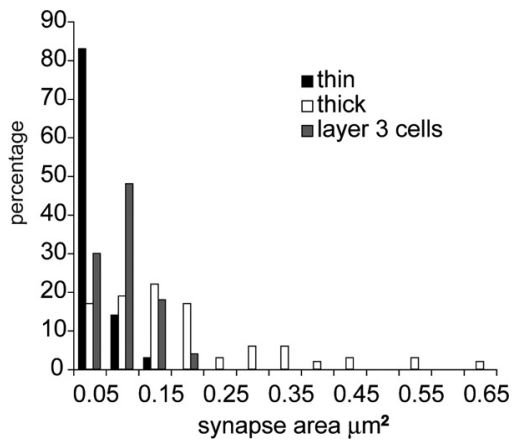

Figure 13. Histograms of the distributions of postsynaptic density areas (in square micrometers) formed by labeled V2 boutons in superficial layers of V1. Shown are thin axon (black, $n=44$ ), thick axon (white, $n=61$ ), and layer 3 pyramidal cells (gray, $n=27$ ).

al., 2001), so that our measures of PSD size may give a qualitative indication of synaptic strength.

\section{Synaptic interrelationships}

The V1 to V2 axons in layer 4 formed $72 \%$ of their synapses with pyramidal dendritic spines. This is comparable to the projections from V2 to V3A (76\%) (Anderson and Martin, 2005) and V2 to MT (67\%) (Anderson and Martin, 2002), but is different from the V1 to MT projection, which forms significantly fewer spine synapses (54\%) (Anderson et al., 1998) due to some large boutons that form multiple somatic synapses. The projection from 

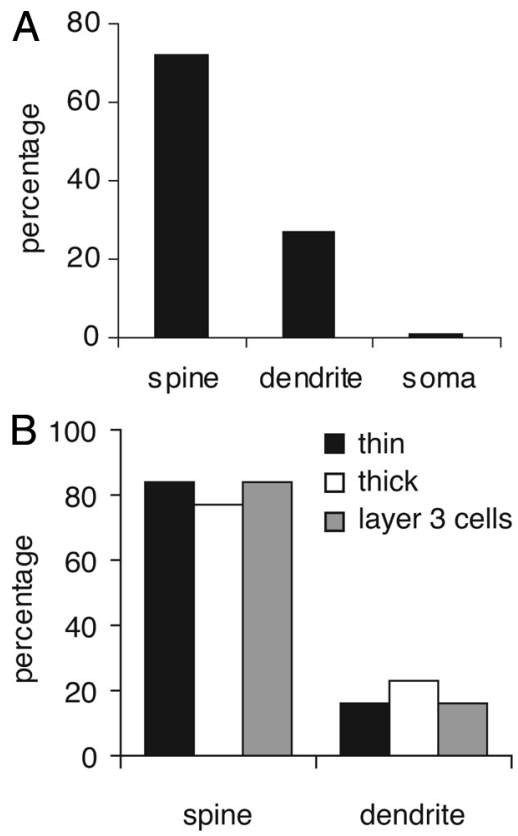

Figure 14. $A$, Histogram of the synaptic targets of labeled V1 boutons in area V2. Spine $n=$ 91, dendrite $n=34$, soma $n=1$. $\boldsymbol{B}$, Histogram of the synaptic targets of the boutons of two labeled $\mathrm{V} 2$ axons in layer 1 of area $\mathrm{V} 1$ and a group of labeled synapses in layers 1 and $2 / 3$ of $\mathrm{V} 1$ from superficial layer 3 pyramidal cells in V2. For the thin axon, $n=44$, and for the thick axon, $n=61$. For the group of V2-labeled layer 3 cell boutons in V1, $n=60$.
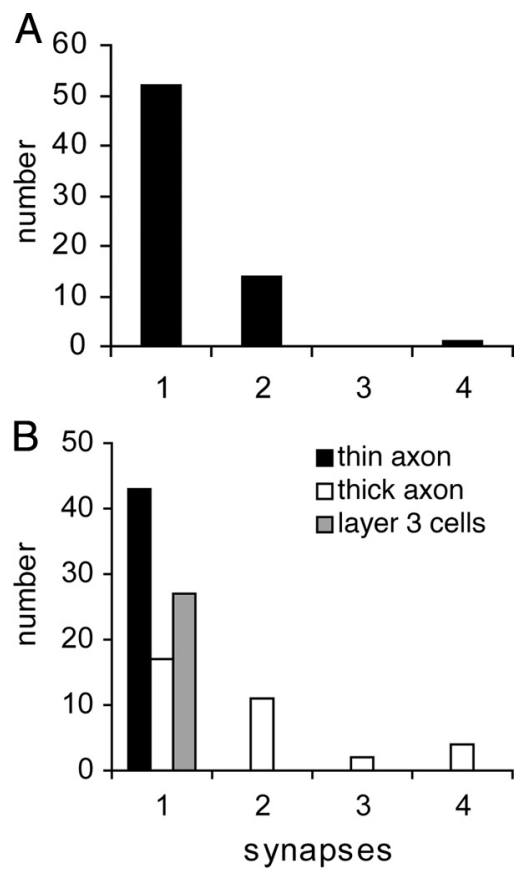

Figure 15. A, Histogram of the number of synapses formed per labeled V1 bouton in layer 4 of area V2. $\boldsymbol{B}$, Histogram of the number of synapses formed per labeled V 2 bouton in superficial layers of area $\mathrm{V} 1$.

V2 to V1 also targeted mainly spines ( $84 \%$ and $77 \%$ for the two axons) in layer 1 , which is its primary layer of innervation. These targets are comparable to the projection to layer 1 in the V4 to V2 pathway (75\%) (Anderson and Martin, 2006). This is different from the rat, where the ascending projection from primary visual cortex to extrastriate cortex formed $90 \%$ of its synapses with spines, while the descending projection formed $98 \%$ of its syn- apses with spines (Johnson and Burkhalter, 1996). Our results for putative GABAergic targets (V1 to V2 and V2 to V1; 14\%).

The pattern of projection of V2 to V1 resembles that of V4 to V2 (Anderson and Martin, 2006) in that two morphologically distinct axons stream through layer 1 . The most common in the $\mathrm{V} 4$ to $\mathrm{V} 2$ projection were axons with boutons (many terminaux) covering the entire length of axon. A second, rarer morphology was that of thicker axons and boutons (mostly en passant) arranged in discrete grape-like clusters. Both these distinct axon morphologies appear in descending pathways [e.g., V4 to V2 (Anderson and Martin, 2006) and area TE to TEO (Suzuki et al., 2000)], and functionally they are likely to have different roles, since it seems likely that different cell types would be the source of such different axon morphologies, as is evident for the local axon collaterals in cat and monkey (Martin and Whitteridge, 1984; Anderson et al., 1993).

\section{The asymmetric relationship between $\mathrm{V} 1$ and $\mathrm{V} 2$}

$\mathrm{V} 1$ is at the root of the tree of visual cortical areas, and so we are not surprised that cooling V1 eliminates all activity in V2 (Girard and Bullier, 1989). However, on the basis of the comparable magnitudes of the projection between V1 and V2 (Barone et al., 2000; Kennedy et al., 2000), we would not predict that inactivating V2 would have a negligible effect on most V1 neurons, but it does (Hupé et al., 2001), even though electrical stimulation showed that V2 neurons can activate V1 neurons with similar latencies to the activation of V2 by V1 neurons (Girard et al., 2001).

Thus, although V1 and V2 are very tightly coupled, the asymmetry of their physiological influence on one another is profound. However, our structural data challenges the notion that the marked difference in their effects can be explained on the basis of fundamental differences in axonal morphology and synapse size or target. Thus, instead of tackling the general question posed by Bullier (2006), "What is fed back?" we can try to answer the simpler question of what factors other than numbers of synapses or their physiology might explain this asymmetry of effect between V1 and V2.

In our studies of the long-distance projections in cat and monkey, we have been struck by the small numbers of synapses they provide to their target areas (Anderson et al., 1998; Latawiec et al., 2000; Anderson and Martin, 2002, 2005, 2006). The largest projection we have seen numerically is from the lateral geniculate nucleus, which provides only $10 \%$ of the excitatory synapses in layer 4 (and $<1 \%$ of all excitatory synapses in area 17 ). Of course, theoretically, if there is the strong constraint of minimizing wiring, whether in brains or silicon chips (Mead, 1989), longdistance connections should be reduced to the minimum.

However, there are perils in wire minimization: in simulations with a biophysically realistic model of spiny stellate cells in layer 4 (Banitt et al., 2007), we discovered that even with optimally oriented stimulation, additional "background" excitation is required to depolarize the cells sufficiently to enable the small modulated LGN inputs to drive the cells to spike. At nonoptimal orientations, the unmodulated excitation from the LGN did not reach threshold. This resembles stochastic resonance. Such observations have led us to propose that the brain does attempt to minimize wire and adds a second important constraint: time. To drive a neuron to threshold, sufficient excitation must arrive within a narrow temporal window. We summarized these two constraints as "just-enough, just-in-time" (Douglas and Martin, 2007).

We can now offer a different interpretation of the structural and functional relationship between V1 and V2. Our hypothesis 
is that differential effects seen with inactivation are not because of synaptic numbers and/or synaptic location or physiology, but simply because V1 provides V2 with a much tighter temporal window of excitation than V2 does V1, at least most of the time. As with the analogy of the orientation model, the more temporally dispersed input from V2 to V1 can be effective in assisting a second modulated input to be effective, but itself is subthreshold and invisible to an extracellular electrode. However, some stimuli might evoke similarly short epochs of excitation in V2 and so enable it to evoke spikes in V1 neurons. Thus, the rigid feedforward and feedback pathway is substituted by a more dynamic interaction where the direction of effective action depends on the stimulus being processed. This hypothesis accounts for the observed functional asymmetry seen between areas, and may be a general principle of cortical wiring and operation. Importantly, it is experimentally testable.

\section{References}

Ahmed B, Anderson JC, Martin KAC, Nelson JC (1997) Map of the synapses onto layer 4 basket cells of the primary visual cortex of the cat. J Comp Neurol 380:230-242.

Anderson JC, Martin KAC (2001) Does bouton morphology optimize axon length? Nat Neurosci 4:1166-1167.

Anderson JC, Martin KAC (2002) Connection from cortical area V2 to MT in macaque monkey. J Comp Neurol 443:56-70.

Anderson JC, Martin KAC (2005) Connection from cortical area V2 to V3A in macaque monkey. J Comp Neurol 488:320-330.

Anderson JC, Martin KAC (2006) Synaptic connection from cortical area V4 to V2 in macaque monkey. J Comp Neurol 495:709-721.

Anderson JC, Martin KAC, Whitteridge D (1993) Form, function, and intracortical projections of neurons in the striate cortex of the monkey Macacus nemestrinus. Cereb Cortex 3:412-420.

Anderson JC, Binzegger T, Martin KAC, Rockland KS (1998) The connection from cortical area V1 to V5: a light and electron microscopic study. J Neurosci 18:10525-10540.

Banitt Y, Martin KAC, Segev I (2007) A biologically realistic model of contrast invariant orientation tuning by thalamocortical synaptic depression. J Neurosci 27:10230-10239.

Barone P, Batardiere A, Knoblauch K, Kennedy H (2000) Laminar distribution of neurons in extrastriate areas projecting to visual area V1 and V4 correlates with the hierarchical rank and indicates the operation of a distance rule. J Neurosci 20:3263-3281.

Beaulieu C, Kisvarday Z, Somogyi P, Cynader M, Cowey A (1992) Quantitative distribution of GABA-immunopositive and -immunonegative neurons and synapses in the monkey striate cortex (area 17). Cereb Cortex 2:295-309.

Bullier J (2006) What is fed back? In: 23 Problems in systems neuroscience (van Hemmen JL, Sejnowsky TJ, eds), pp 103-132. New York: Oxford UP.

Dehay C, Douglas RJ, Martin KAC, Nelson C (1991) Excitation by geniculocortical synapses is not "vetoed" at the level of dendritic spines in cat visual cortex. J Physiol 440:723-734.

Douglas RJ, Martin KAC (2007) Recurrent neuronal circuits in the neocortex. Curr Biol 17:R496-R500.

Felleman DJ, Van Essen DC (1991) Distributed hierarchical processing in the primate cerebral cortex. Cereb Cortex 1:1-47.

Friedlander MJ, Martin KAC, Wassenhove-McCarthy D (1991) Effects of monocular visual deprivation on geniculocortical innervation of area 18 in the cat. J Neurosci 11:3268-3288.

Girard P, Bullier J (1989) Visual activity in area V2 during reversible inactivation of area 17 in the macaque monkey. J Neurophysiol 62:1287-1302.

Girard P, Hupé JM, Bullier J (2001) Feedforward and feedback connections between areas V1 and V2 of the monkey have similar rapid conduction velocities. J Neurophysiol 85:1328-1331.

Guillery RW, Sherman SM (2002) Thalamic relay functions and their role in corticocortical communication: generalizations from the visual system. Neuron 33:163-175.

Harris KM, Stevens JK (1989) Dendritic spines of CA1 pyramidal cells in the rat hippocampus: serial electron microscopy with reference to their biophysical characteristics. J Neurosci 9:2982-2997.

Hupé J-M, James AC, Girard P, Bullier J (2001) Response modulations by static texture surround in area $\mathrm{V} 1$ of the macaque monkey do not depend on feedback connections from V2. J Neurophysiol 85:146-163.

Johnson RR, Burkhalter A (1996) microcircuitry of forward and feedback connections within rat visual cortex. J Comp Neurol 368:383-398.

Kennedy H, Barone P, Falchier A (2000) Relative contribution of feedforward and feedback inputs to individual areas. Eur J Neurosci 12 [Suppl 11]:489.

Kisvárday ZF, Martin KAC, Whitteridge D, Somogyi P (1985) Synaptic connections of intracellularly filled clutch neurons, a type of small basket neuron in the visual cortex of the cat. J Comp Neurol 241:111-137.

Knott GW, Holtmaat A, Wilbrecht L, Welker E, Svoboda K (2006) Spine growth precedes synapse formation in the adult neocortex in vivo. Nat Neurosci 9:1117-1124.

Latawiec D, Martin KAC, Meskenaite V (2000) Termination of the geniculocortical projection in the striate cortex of macaque monkey: a quantitative immunoelectron microscopy study. J Comp Neurol 419:309-319.

Livingstone MS, Hubel DH (1983) Specificity of cortico-cortical connections in monkey visual system. Nature 304:531-534.

Livingstone MS, Hubel DH (1984) Anatomy and physiology of a color system in the primate visual cortex. J Neurosci 4:309-356.

Martin KAC, Whitteridge D (1984) Form, function and intracortical projections of neurones in the striate cortex of the cat. J Physiol 353:463-504.

Mead C (1989) Analog VLSI and neural systems. Reading, MA: Addison-Wesley.

Meskenaite V (1997) Calretinin-immunoreactive local circuit neurons in area 17 of the cynomolgus monkey, Macaca fascicularis. J Comp Neurol 379:113-132.

Murthy VN, Schikorski T, Stevens CF, Zhu Y (2001) Inactivity produces increases in neurotransmitter release and synapse size. Neuron 32:673-682.

Peters A, Saint Marie R (1984) Smooth and sparsely spinous non-pyramidal cells forming local axonal plexuses. In: Cerebral cortex, Vol 1. Cellular components of the cerebral cortex (Jones EG, Peters A, eds), pp 419-445. New York: Plenum.

Peters A, Palay SL, Webster Hd (1991) The fine structure of the nervous system: neurons and their supporting cells, Ed 3. Oxford: Oxford UP.

Rockland KS (1994) The organization of feedback connections from area V2 (18) to V1 (17). In: Cerebral cortex (Peters A, Rockland KS, eds), Vol 10, pp 243-293. New York: Plenum.

Rockland KS, Knutson T (2001) Axon collaterals of Meynert cells diverge over large portions of area V1 in the macaque monkey. J Comp Neurol 441:134-147.

Rockland KS, Virga A (1989) Terminal arbors of individual "feedback" axons projecting from area V2 to V1 in the macaque monkey: a study using immunohistochemistry of anterogradely transported Phaseolus vulgarisleucoagglutinin. J Comp Neurol 285:54-72.

Rockland KS, Virga A (1990) Organization of individual cortical axons projecting from area V1 (area 17) to V2 in the macaque monkey. Vis Neurosci 4:11-28.

Schikorski T, Stevens CF (1997) Quantitative ultrastructural analysis of hippocampal excitatory synapses. J Neurosci 17:5858-5867.

Sincich LC, Horton JC (2002a) Divided by cytochrome oxidase: a map of the projections from V1 to V2 in macaques. Science 295:1734-1737.

Sincich LC, Horton JC (2002b) Pale cytochrome oxidase stripes in V2 receive the richest projection from macaque striate cortex. J Comp Neurol 447:18-33.

Sincich LC, Horton JC (2005a) Input to V2 thin stripes arises from V1 cytochrome oxidase patches. J Neurosci 25:10087-10093.

Sincich LC, Horton JC (2005b) The circuitry of V1 and V2: integration of color, form, and motion. Annu Rev Neurosci 28:303-326.

Somogyi P, Kisvárday ZF, Martin KAC, Whitteridge D (1983) Synaptic connections of morphologically identified and physiologically characterized large basket cells in the striate cortex of cat. Neuroscience 10:261-294.

Suzuki W, Saleem KS, Tanaka K (2000) Divergent backward projection from the anterior part of the inferotemporal cortex (area TE) in the macaque. J Comp Neurol 422:206-228. 